\title{
SHEAR RESISTANCE AND DUCTILITY OF RC COLUMNS AFTER YIELD OF MAIN REINFORCEMENT
}

\author{
Xuehui $\mathrm{AN}^{1}$ and Koichi MAEKAWA ${ }^{2}$ \\ ${ }^{1}$ Member of JSCE, Dr. of Eng., Seismic Engineering Dept., Tokyo Electric Power Services Co., Ltd., (Higashi-Ueno \\ 3-3-3, Taito-ku, Tokyo 110, Japan) \\ ${ }^{2}$ Member of JSCE, Dr. of Eng., Professor, Department of Civil Engineering, The University of Tokyo, \\ (Hongo 7-3-1, Bunkyo-ku, Tokyo 113, Japan)
}

\begin{abstract}
During Hanshin-Awaji Earthquake, catastrophic shear failure accompanying plenty of diagonal shear cracks were experienced in RC structures and bridge piers serving transportation facilities. In this paper, shear capacity and ductility of RC columns in the post-yield range of longitudinal reinforcement are discussed for seismic resistant design. First, the shear failure of large scale RC column is computationally simulated for understanding the mechanism of shear collapse of bridge piers. FEM computational results on ductility are compared with the experiments and parametric study is conducted concerning factors that affect the post-yield deformability of RC columns. Finally, a simple formula for ductility is presented for summarizing the sensitivity of influential factors.
\end{abstract}

Key Words : shear failure, ductility, diagonal crack, RC column, FEM, size effect

\section{INTRODUCTION}

Through the investigation of $\mathrm{RC}$ columns for bridge piers that failed in Hanshin-Awaji Earthquake ${ }^{1)}$, two kinds of typical damages occurring in columns with different dimensional features were found. For columns with smaller section and large span to depth ratio, greater deformation is thought to follow yielding of main reinforcement accompanying residual flexural crack opening (Fig. 1a). But no catastrophic collapse occurred in this kind of RC columns. The columns could still sustain super-structures and continued to serve as bridge piers. This is an important point in view of conservation of transportation capability. The repair of RC columns damaged in flexural mode was not so difficult in practice.

Another kind of damage is an unstable and brittle catastrophic shear failure. There are many RC piers with comparatively smaller shear span to depth ratio, larger scale of the sections, small main reinforcement ratio and much less web reinforcement. After the earthquake, shear cracks were clearly observed in these columns (Fig. 1b). It seems that these RC columns with diagonal shear cracks lose the load carrying mechanism just after the shear failure and suddenly stop working as bridge piers. This kind of collapse is generally dangerous and should be avoided even in the case of strong earthquake beyond expectation. In this paper, the shear collapse

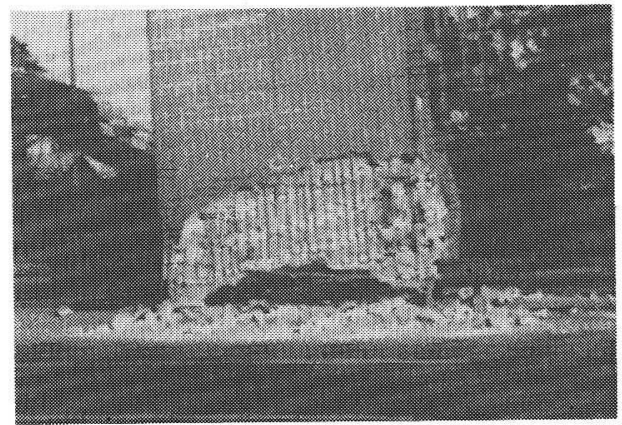

Fig. 1a Flexural damage after yielding of main reinforcement.

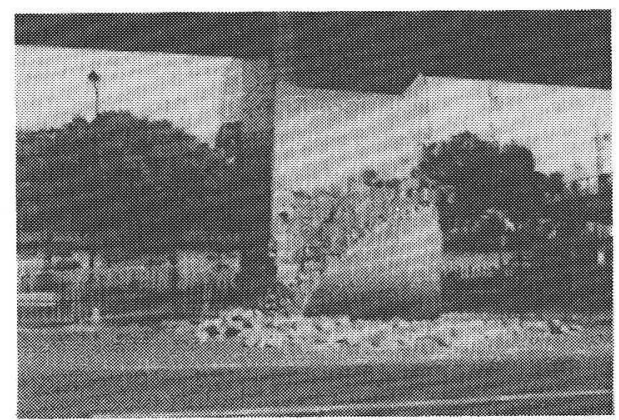

Fig. 1b Damaged column with diagonal shear cracking.

mechanism and ductility of RC column in the postyield range of reinforcement are discussed and numerically simulated for understanding the reduction of intrinsic shear capacity associated with deformation. 


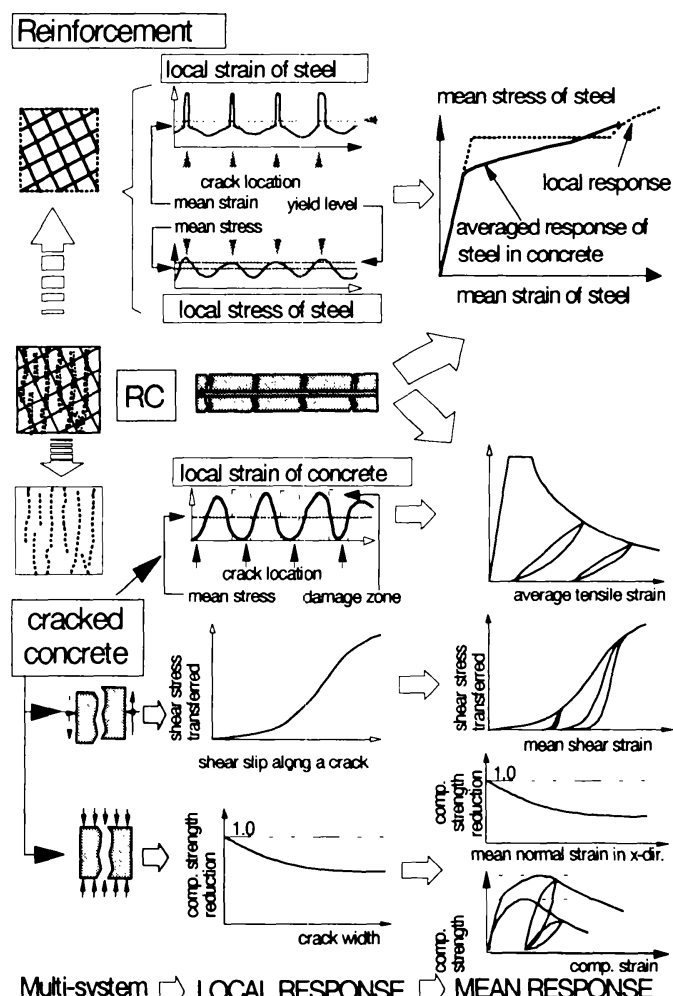

Fig. 2 Cracked concrete model in RC zone ${ }^{4)}$.

\section{NONLINEAR CONSTITUTIVE MODELS AND VERIFICATIONS}

\section{(1) Constitutive models applied to RC columns}

Constitutive models were proposed to simulate behaviors of RC members by finite element method for engineering proposes ${ }^{2)}$ based on the smeared crack approach applied to finite control domains including distributed fixed multi-directional cracks. Here, all stress-strain relationships are indicated in terms of the spatial average stress and average strain of concrete defined in finite elements. This chapter just summarizes the model used in the shear analysis, since the reference (2) offers details.

\section{a) Cracked concrete model in $\mathrm{RC}$ zone $\mathrm{e}^{3 \text { ) }}$}

The reinforced concrete model was constructed by combining the constitutive law for concrete and that for reinforcing bars (Fig. 2). The constitutive law adopted for the cracked concrete consists of tension stiffness, compression and shear transfer models.

Once cracks are generated in concrete, anisotropy becomes significant so that stress-strain relationship takes on an orthogonal anisotropy along a crack direction. The stress-strain relations are modeled being decomposed in the directions parallel, along and normal to cracks, respectively.

Owing to bond action between concrete and reinforcing bars, concrete continues to support a part of tensile force even after cracks occur dispersedly in reinforced concrete zones. For considering bond effects on RC deformation, a relation between the average stress and average strain of concrete is given as a macroscopic tension model for cracked concrete. This tension model mechanically describes how the tensile stress is transferred from steel bars to concrete beyond cracks by bond.

This constitutive law for reinforced concrete, which derives from a control volume of $30-50 \mathrm{~cm}$ sized concrete element with distributed cracks, is independent of crack spacing owing to the trade-off mechanism among bond deterioration zones and its development length ${ }^{5}$. It is verified that in the case of normal concrete and two-way reinforcement with the ratio over $0.1 \%$ up to $2 \%$, this constitutive law is independent of the size of control volume unlike plain concrete. This cracked concrete model is rather simple as the mean behavior of cracked concrete is unrelated to spacing of cracks, direction of reinforcing bars and reinforcement ratio without any size sensitivity ${ }^{5}$.

The shear transfer model of cracked concrete in $\mathrm{RC}$ is based on the contact density idealization ${ }^{6}$.

It was mathematically and experimentally proved that the shear stiffness of cracked concrete zone is not affected by the crack spacing and density ${ }^{3), 5}$. It means element-size insensitivity of shear behavior along cracks in RC zone.

\section{b) Effective size of $\mathrm{RC}$ zone}

We cannot expect mean stress transfer through bond around some parts which do not contain any reinforcement and tension stiffness mechanism does not reach. The authors raised zoning of the whole structural volumes into RC zone and plain one and the effective size of RC zone was discussed as one of influential factors for size effect compuation ${ }^{2)}$. Different size of RC zone in an analysis domain has its effect not only on the stiffness of member after cracking, but also the failure mode which may change from shear to flexure as a size of RC zone increases. The mechanical feature of reinforced/plain concrete zoning related to the volume of crack propagation stability was investigated by the authors with respect to the size effect in shear capacity of RC members before yield of longitudinal reinforcement ${ }^{2}$. This paper aims at the same discussion in view of the post-yield behavior of RC members in shear. 


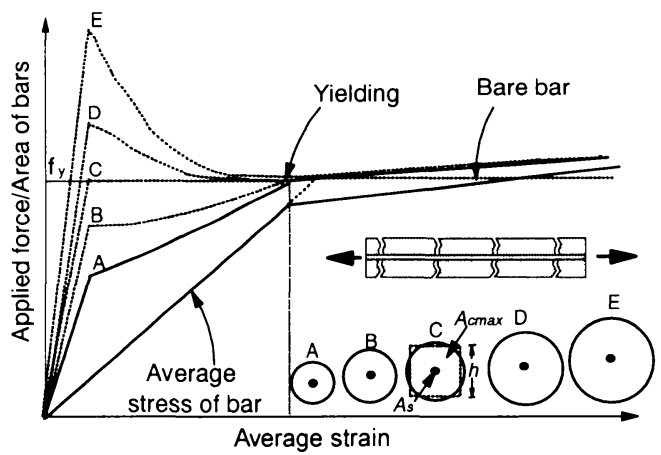

Fig. 3 Crack control capability and concrete area.

The size of RC zone was proposed to be associated with the tension stress transfer mechanism by bond characteristics stated in the previous section. As a critical case as shown in Fig.3, if a reinforced concrete member subjected to tension contains small amount of reinforcement, reinforcing bars crossing the crack may yield just after cracking and most inelastic deformation will be rooted in the sole crack. This is a critical point whether the adequate crack control capability with several cracks be obtained. For a certain steel bar, we have the maximum size of reinforced concrete zone where stable cracks can develop as,

$$
A_{c \max }=\frac{A_{s} \cdot f_{y}}{f_{t}}
$$

where, $A_{s}$ :area of steel bar, $A_{\text {cmax }}$ :maximum area of bond effective zone in concrete, $f_{y}$ :yielding strength of steel bar. In two dimensional computation ${ }^{2}$, it was proposed to use the relation of $\mathrm{RC}$ zone height as shown in Fig.3 and steel bar diameter as,

$$
h_{\max }=\frac{\sqrt{\pi}}{2} \cdot d_{b} \cdot \sqrt{\frac{f_{y}}{f_{t}}}
$$

where, $h_{\max }$ is height of RC zone and we have $A_{c \max }=$ $h_{\max }{ }^{2}, d_{b}$ is diameter of reinforcing bar.

The formula above is the case where cover is thick enough to avoid splitting failure ${ }^{7}$. If not, the capability of a deformed bar to transfer its load into the surrounding concrete is considerably limited by splitting failure along the axis of bars. Experimental studies to confirm the cover effects in the longitudinal splitting crack formation were conducted $^{8}$. Some results of the relation between bond strength and the specific cover are shown in Fig. 4. The bond capacity decreases as the concrete cover decreases. For insufficient cover, the formula in Eq.(5) was proposed to be factorized by an empirical function $\mathrm{K}$ based on test result ${ }^{2)}$ as,

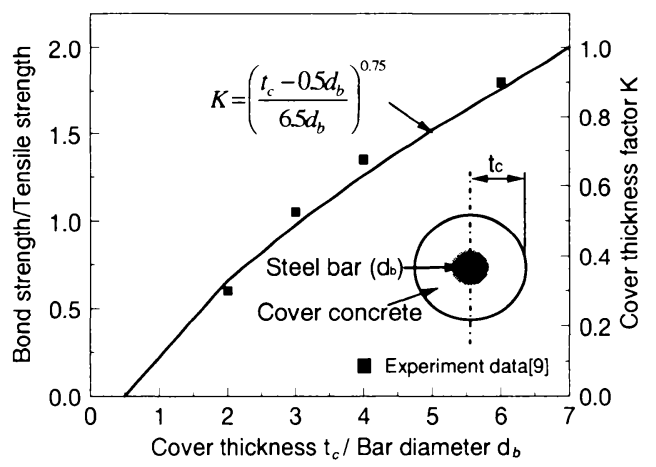

Fig. 4 Cover effect on bond strength and factor $K$.

$$
K=\left(\frac{t_{c}-0.5 d_{b}}{6.5 d_{b}}\right)^{0.75}
$$

where, $K$ : modification factor on cover thickness, $K=0$ when $t_{c}<0.5 d_{b}$ and $K=1$ when $t_{c}>7 d_{b}$ and $t_{c}$ : thickness of concrete cover.

In two dimensional finite element computation, it is needed to decide the height of RC zone of steel bars with wider variety of arrangement. The proposed basic rule ${ }^{2)}$ was that the height of RC zone is decided by the diameter of each bar. If a larger bar diameter is used, the RC zone gets higher (Fig.5a).

Another extreme case to be considered is that steel bars are placed away from each other. The size of RC zone may be smaller than that computed by Eq.(5), as the steel bar can not control the crack distribution in the whole volume of concrete in the width (Fig.5b). Then, the height of RC zone used in computation was hereafter proposed as,

$$
h_{e}=\frac{n \cdot h_{\max }^{2}}{b}
$$

where, $h_{e}$ : modified hight of RC zone, $n:$ numbers of steel bars, $b$ : thickness of RC member.

When arranged bars are so small or placed away from each other, it is needed to consider the situation that one element contains both RC and plain concrete (PL) zones. The arranged stress-strain curve of this element with mixed zones can be decided by solving Eq.(8) of fracture energy balance ${ }^{2)}$ in terms of $c_{m}$ as,

$\int_{0}^{\infty} \sigma_{t}\left(\varepsilon_{t} ; c_{m}\right) d \varepsilon_{t}=\frac{\left(l_{e}-h_{e}\right) \int_{0}^{\infty} \sigma_{P L} d \varepsilon_{t}+h_{e} \int_{0}^{\infty} \sigma_{R C} d \varepsilon_{t}}{l_{e}}$

where, $\sigma_{R C}=\sigma_{t}\left(\varepsilon_{t} ; 0.4 \vee 0.2\right)$ in Eq.(2) and $\sigma_{P L}=\sigma_{t}\left(\varepsilon_{t} ; c_{p l}\right)$ where $c_{p l}$ is defined later.

$l_{e}:$ height of the finite element. 


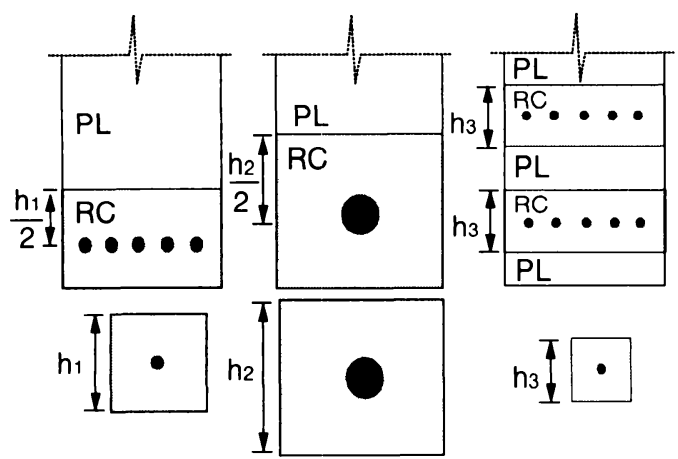

(a) RC zone definition in computation. $\left(h_{n} \leq h_{\max }\right)$.

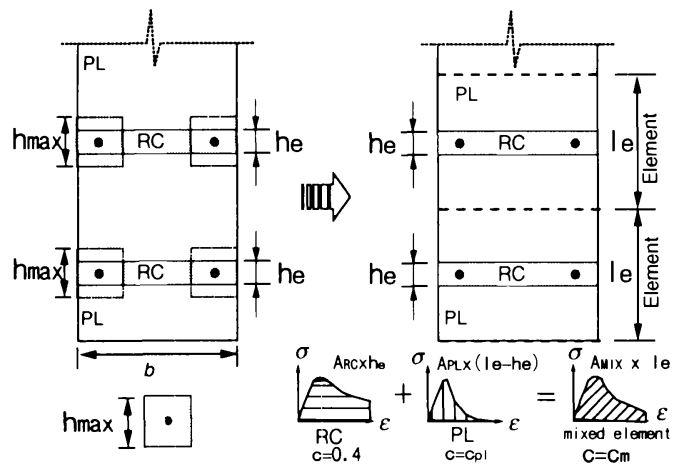

(b) RC zone with bars of large distance. $\left(h_{e}<h_{\max }\right)$.

Fig. 5 RC zoning method.

\section{c) Cracked concrete model in PL zone}

Cracked plain concrete shows strain-softening characteristics in tension and shear unlike concrete confined by reinforcing bars. Here, the mean stressstrain relation turns to be element-size dependent and is formulated with respect to the fracture energy ${ }^{9}$. Based on the fracture energy balance, the average stress-strain curve defined in an element is adjusted according to the reference length $l_{r}$ which is the square root of the element area as shown in Fig. 6. In the proposed model of the authors ${ }^{2)}$, the tension factor denoted by "c" is inversely decided with the element size by getting the constant fracture energy. Fig. 6 gives a series of tensile stress-strain curves used for the following analysis.

Here we have the same discussion in shear mode. Bujadham model ${ }^{26)}$ presents contact softening in shear transfer. A simplified softening model which is equivalent to the original model was proposed, that is, when the shear strain reaches the ultimate value, the shear softening begins (Fig. 7). Since the shear transfer mechanism is highly frictional, no unique shear softening energy is available but dependent on the confinement normal to cracks.

The proposed model in crack shear is also performed as the combination of cracked concrete

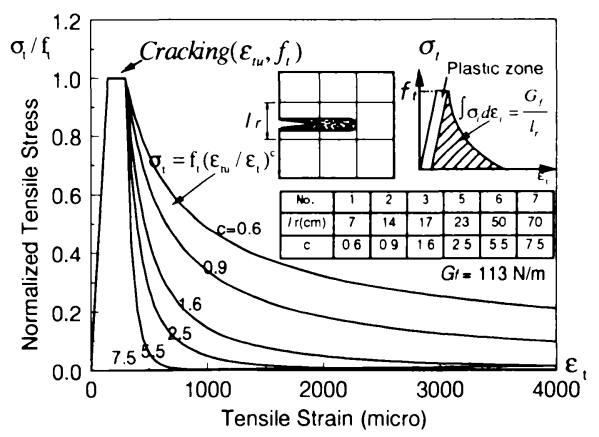

Fig. 6 Tension stress-strain softening curve in computation.

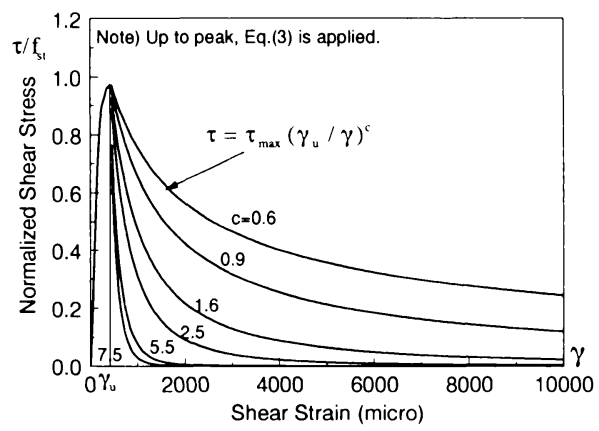

Fig. 7 Shear stress-strain softening curve for plain concrete. (tensile strain $=0.00005$, ultimate shear strain $\gamma_{u}=0.0004$ )

model in RC zone and PL zone, based on the RC zoning method.

\section{(2) Verification of proposed models}

FEM code WCOMD-SJ in which the proposed models are installed presents computations for size effect experiment ${ }^{4)}$ as shown in Fig. 8. This size effect experiment consists of large RC beams without shear reinforcement having different effective depth from $10 \mathrm{~cm}$ to $300 \mathrm{~cm}$. The specified properties are listed in Table 1 . The main reinforcement ratio in the vicinity of support points where shear failure would occur is taken to be $0.4 \%$. The beams were loaded by uniformly distributed hydraulic pressure until failure. The observed failure modes were flexural failure for beam No.1 and No. 2 and the shear failure for the other beams left.

The shear strength estimated by the JSCE code equation ${ }^{10)}$ is also drawn in Fig. 8 for comparison. It can be seen that the proposed model predicts shear strength with size effect and has fair agreement with the JSCE code prediction. The crack pattern in Fig. 8 also shows that the computation can simulate the crack development and failure mode correctly ${ }^{2}$.

For verification with respect to reinforcement ratio $\rho$ and compressive strength $f_{\mathrm{c}}^{\prime}$, computational results for beam with changing $\rho$ and $f_{\mathrm{c}}^{\prime}$ are plotted 
Table 1 Specified properties of RC beams ${ }^{4)}$.

\begin{tabular}{|c|c|c|c|c|}
\hline & Depth & $\begin{array}{c}\text { Concrete } \\
\text { strength }\end{array}$ & Shear Strength & $\begin{array}{c}\text { Shear } \\
\text { Strength }\end{array}$ \\
\hline & $\mathrm{d}$ & $\mathrm{f}_{\mathrm{c}}$ & Exp. & Comp. \\
\hline & $\mathrm{cm}$ & $\mathrm{kgf} / \mathrm{cm}^{2}$ & $\mathrm{kgf} / \mathrm{cm}^{2}$ & $\mathrm{kgf} / \mathrm{cm}^{2}$ \\
\hline 1 & 10 & 202 & $(7.38)$ & $(6.75)$ \\
\hline 2 & 20 & 193 & $(8.41)$ & $(7.02)$ \\
\hline 3 & 60 & 207 & 4.55 & 4.59 \\
\hline 5 & 100 & 215 & 3.87 & 4.05 \\
\hline 6 & 200 & 279 & 3.40 & 3.51 \\
\hline 7 & 300 & 240 & 3.09 & 3.24 \\
\hline
\end{tabular}
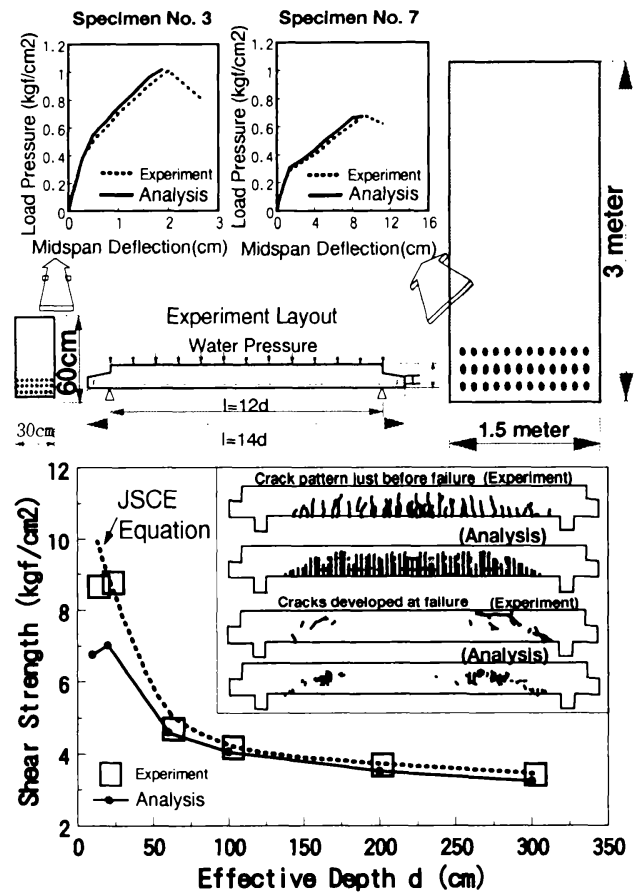

Fig. 8 Computational results and size effect oriented experiments ${ }^{2)}$.

in Fig. 9. The predicted shear strength is proportional to $\rho^{1 / 3}$ and $f_{\mathrm{c}}^{\prime}{ }^{1 / 3}$ similar to the sensitivity of the JSCE equation. Since the JSCE shear strength equation is capable of predicting the reality within $10 \%$ of coefficient of variation, it may be used for indirect experimental verification of the FEM computation.

\section{(3) Nonlinear characteristics of concrete partly confined by web reinforcement}

As discussed in the previous section, concrete in RC exhibits different post-cracking nonlinearity from place to place in both tension and shear, and shows brittleness when located apart from reinforcement. For dealing with cracked concrete in different part of structures, the proposed models in section (1) are adopted in studying the larger scale $\mathrm{RC}$ columns, too.
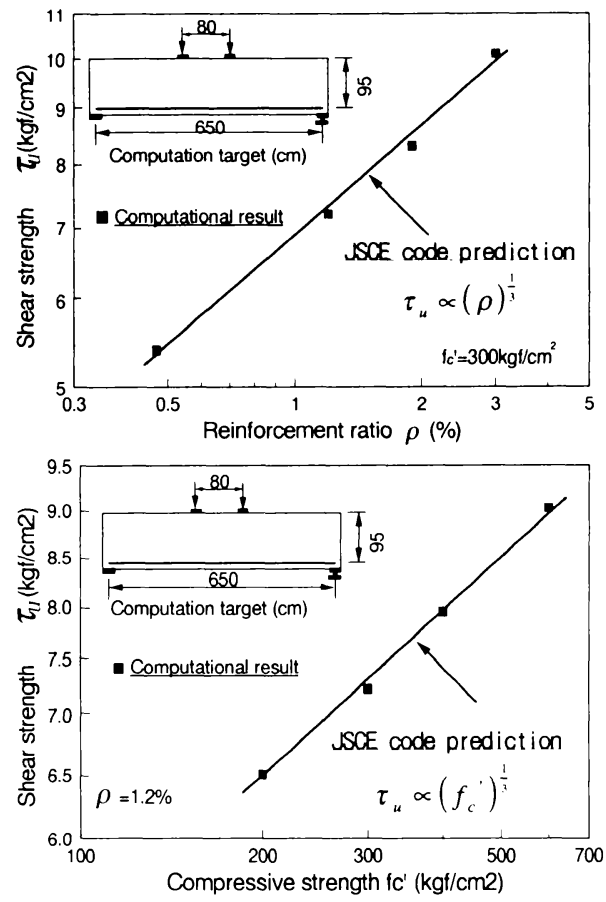

Fig. 9 Effect of reinforcement ratio and concrete compressive strength on nominal shear strength.

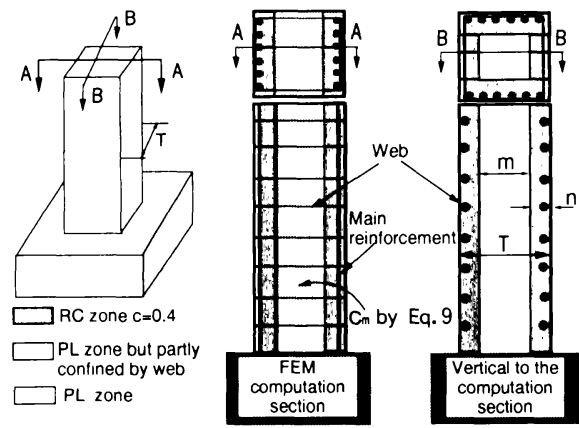

Fig. 10 Zoning for RC column with few web reinforcement.

For dealing with large scale RC columns with web reinforcement, it is required to consider threedimensional arrangement of web bars and its mechanical conversion to two-dimensional analysis as shown in Fig. 10. In section (1), the mixed element was proposed for FEM elements including $\mathrm{RC}$ and plain zones aiming to simulate the effect of longitudinal steel bars with large distance in beam analysis. Here, the authors adopted this concept similarly to web portions including lateral bars with large distance (Fig. 10).

Let $\mathrm{n}$ and $\mathrm{m}$ denote the thickness of $\mathrm{RC}$ skin layers created by web reinforcement as shown in Fig. 10 and the size of plain core of the column in the thickness direction of $2 \mathrm{D}$ projection. The diagonal shear crack based energy release is expected to be 
Table 2 Experiments of shear mode failure after yielding of longitudinal reinforcement.

\begin{tabular}{|c|c|c|c|c|c|c|}
\hline Series No. & 1 & 1 & 1 & 2 & 2 & 3 \\
\hline Ref. & {$[11]$} & {$[11]$} & {$[11]$} & {$[12]$} & {$[12]$} & {$[12]$} \\
\hline Width B (cm) & 80 & 80 & 80 & 40 & 40 & 40 \\
\hline Effective depth d (cm) & 35 & 35 & 35 & 35 & 35 & 35 \\
\hline Shear span to depth ratio a/d & 4.0 & 4.0 & 4.0 & 4.0 & 4.0 & 4.0 \\
\hline Axial stress $\left(\mathrm{kgf} / \mathrm{cm}^{2}\right)$ & 10 & 10 & 10 & 10 & 10 & 0 \\
\hline Main reinforcement ratio (\%) & 0.86 & 0.86 & 0.86 & 1.66 & 1.66 & 2.48 \\
\hline Web reinforcement ratio (\%) & 0.08 & 0.16 & 0.04 & 0.27 & 0.42 & 0.58 \\
\hline $\mathrm{V}_{\mathrm{c}}\left(\mathrm{kgf}_{\mathrm{cm}} \mathrm{cm}^{2}\right)$ & 7.7 & 7.7 & 7.7 & 9.8 & 9.8 & 11.2 \\
\hline $\mathrm{V}_{\mathrm{s}}\left(\mathrm{kgf} / \mathrm{cm}^{2}\right)$ & 2.1 & 4.2 & 1.1 & 7.9 & 12.3 & 20.2 \\
\hline $\mathrm{P}_{\mathrm{y}}\left(\mathrm{kgf} / \mathrm{cm}^{2}\right)$ & 7.9 & 7.9 & 7.9 & 15.5 & 15.5 & 21.4 \\
\hline$\left(\mathrm{V}_{\mathrm{c}}+\mathrm{V}_{\mathrm{s}}\right) / \mathrm{P}_{\mathrm{y}}$ & 1.30 & 1.53 & 1.14 & 1.23 & 1.56 & 1.46 \\
\hline$\mu(\mathrm{By} \mathrm{test})$ & 3.9 & 4.2 & 3.0 & 5.0 & 7.0 & 5.9 \\
\hline$\mu($ By FEM) & 3.8 & 4.0 & 3.2 & 4.9 & 5.8 & 5.5 \\
\hline Failure mode & shear & shear & shear & shear & shear & shear \\
\hline
\end{tabular}

Note: $\quad V_{c}$ : shear carrying capacity of concrete evaluated based on JSCE specification., $V_{s}:$ shear carrying capacity of web steel based on yielding, (JSCE specification), $P_{y}$ : shear force at which yielding of main reinforcement is brought about, $\mu$ : ductility ratio ( $=\delta_{\mathrm{u}} / \delta_{\mathrm{y}}$, $\delta_{\mathrm{u}}$ : ultimate displacement when diagonal shear failure occurs, $\delta_{\mathrm{y}}$, yield displacement), See Eq.(14)

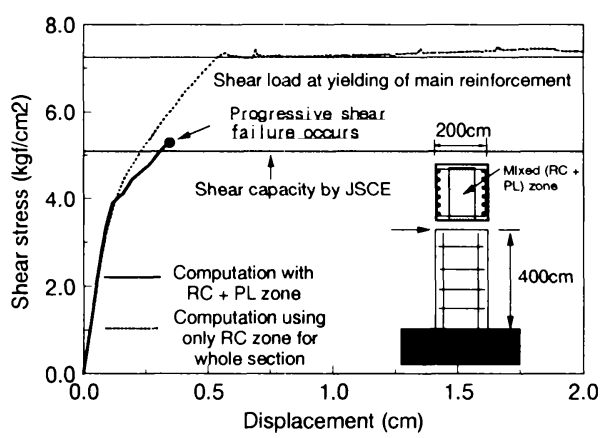

(a) Load-displacement relationship.

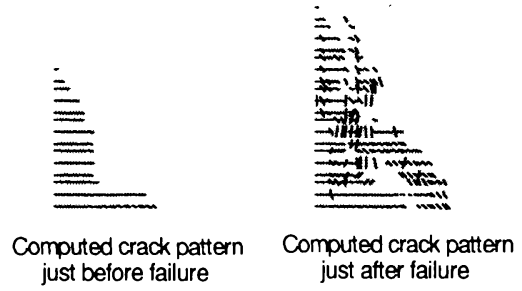

(b) Computed crack patterns.

Fig. 11 Shear failure of RC column with web reinforcements.

sum of energy consumed by both RC skin layers and plain volume. Then, similar to Eq.(8), we have a fracture energy conservation as,

$$
\int_{0}^{\infty} \sigma_{t}\left(\varepsilon_{t} ; c_{m}\right) d \varepsilon_{t}=\frac{m \int_{0}^{\infty} \sigma_{P L} d \varepsilon_{t}+n \int_{0}^{\infty} \sigma_{R C} d \varepsilon_{t}}{(n+m)}
$$

By solving Eq.(9), we have $c_{m}$ for the elements allocated to the web zones of the columns concerned.

An existing RC bridge piers is selected for verification. It has $2 \mathrm{~m} \times 2 \mathrm{~m}$ square section with main reinforcement ratio of $0.4 \%$ and web ratio of $0.05 \%$. The computational result is shown in Fig. 11. The computed nominal shear capacity is $5.3 \mathrm{kgf} / \mathrm{cm}^{2}$. From Fig. 11b the shear crack band at the last unstable failure step is identical. According to the JSCE code, the shear strength of this column is estimated as $5.2 \mathrm{kgf} / \mathrm{cm}^{2}$. The FEM simulation has reasonable agreement with the JSCE prediction.

\section{FAILURE MODE AND DUCTILITY PREDICTION OF RC COLUMNS}

It is well known that ductility of RC column is associated with shear carrying capacity. In ordinary cases, increase in web reinforcement exhibits higher ductility of RC columns and it is clearly shown by experiments $^{(1), 12)}$. Here three experiments are reported with FEM simulation. The first and second cases are with joint element placed between footing and columns. The third one is a reinforced concrete column with side reinforcement.

The experimental details are shown in Table 2. The calculated shear capacities are listed in the table according to the JSCE code prediction and are larger than the shear force when yielding of main reinforcement occurs. Thus, the brittle shear failure before yielding is avoided. But the shear carrying capacity of each specimen is not so high as to exceed two times of shear force at yielding. According to the newly proposed criteria of JSCE ${ }^{13)}$, these specimens are expected to fail in shear mode after yielding of main reinforcement. 
The FEM simulation on ductility associated with shear failure is verified by using the test data. Fig. 12 shows the target of verification from Ref.[11], and Fig. 16 from Ref.[12]. The computed results are shown in Fig.13 and Fig.17. The computational loop will stop at the point that shear strain increases sharply and becomes larger than the critical value (set as $1 \%$ in this research). The displacement at this point is taken as ultimate one, and the ductility at this point is used to compare with that at the point of maximum load in experimental loop, which continues after the peak of load and becomes smaller and smaller. It can be seen that FEM computed results have fair agreement with experimental ones. Both the experimental and computational results show that the increase in web reinforcement ratio in $\mathrm{RC}$ column yields higher ductility. In order to confirm the failure mode in computation, crack patterns of a specimen is shown in Fig. 14, with comparison of the observed shear cracks in experiment. The diagonal crack pattern is seen in experiment and analysis.

In order to confirm the behavior of joint element, the computed pull-out displacement for case 1 is compared with observed data in Fig.15. The total displacement will increase about $30 \%$ because of this pull-out effect.

The FEM simulation for RC column with side reinforcement ${ }^{12)}$ under monotonic load is shown in Fig. 18. It is reported that side reinforcement alerts shear carrying capacity prior to yielding of steel ${ }^{18)}$. The ductility of RC column with side reinforcement after yield of main reinforcement can also be simulated by FEM computation. All these results support that the shear failure and ductility level of $\mathrm{RC}$ column after yielding of main reinforcement can be estimated by FEM analysis proposed in Chapter 2 .

Sectional sizes of all experiments are less than 1 meter. In this section, the shear failure before yielding of longitudinal reinforcement in $2 \mathrm{~m} \times 2 \mathrm{~m}$ scale RC column is simulated by FEM. In order to check the effect of web reinforcement on the failure mode and ductility, additional web reinforcement is placed to the referential case in the sensitivity analysis as listed in Table 3 . The failure mode changes according to the different amount of web reinforcement ratio as calculated in Table 3. First, web reinforcement ratio is specified $0.15 \%$. The total shear capacity is higher than shear load when yield occurs but the shear carrying capacity estimated by the JSCE code practice is much smaller than twice the shear load when yielding occurs. So, the column may fail in shear mode after yield of main longitudinal reinforcement resulting in less ductility.

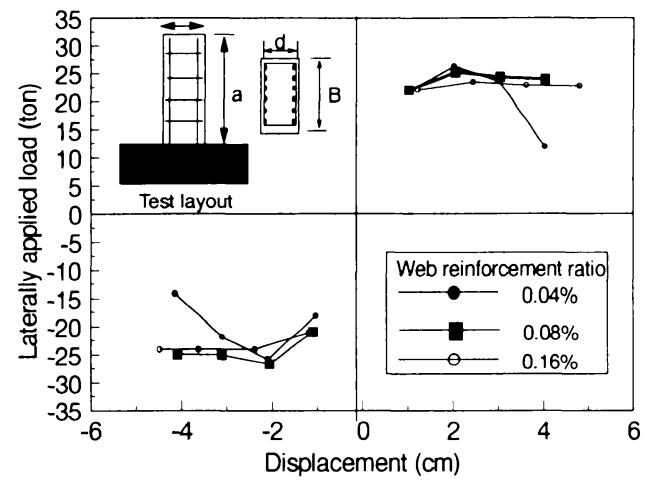

Fig. 12 Envelope of cyclic load-displacement relation of RC columns with different web reinforcement ratios ${ }^{(1)}$.

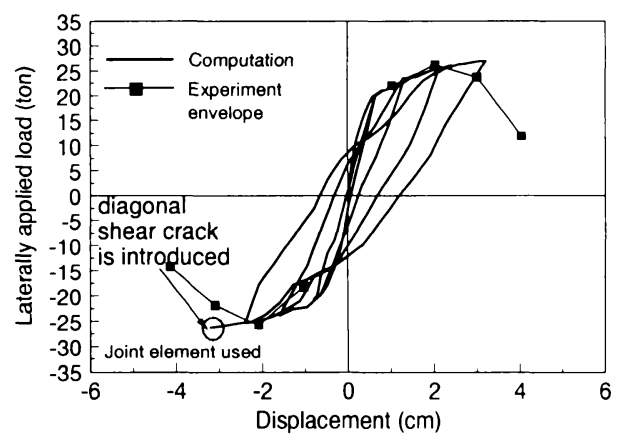

(a) Web reinforcement ratio $=0.04 \%$.

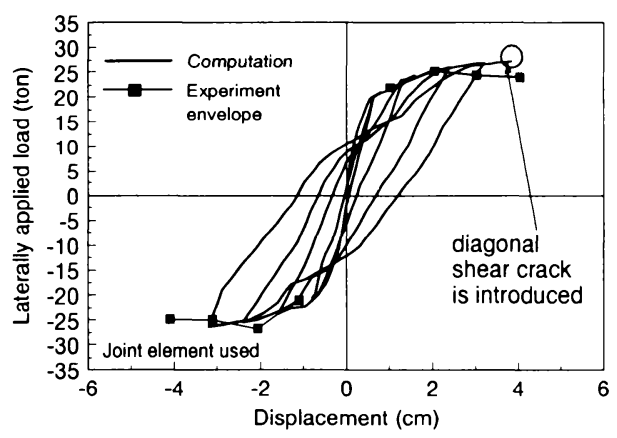

(b) Web reinforcement ratio $=0.08 \%$.

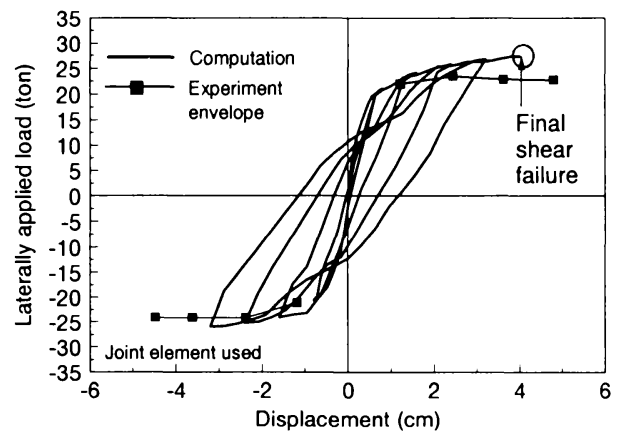

(c) Web reinforcement ratio $=0.16 \%$.

Fig. 13 Computed ductility and hysteretic responses. 


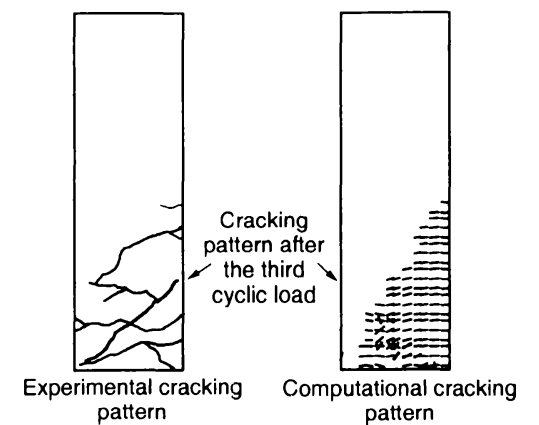

Fig. 14 Crack pattern comparison when shear failure occurs. (web reinforcement ratio $=0.08 \%$ ).

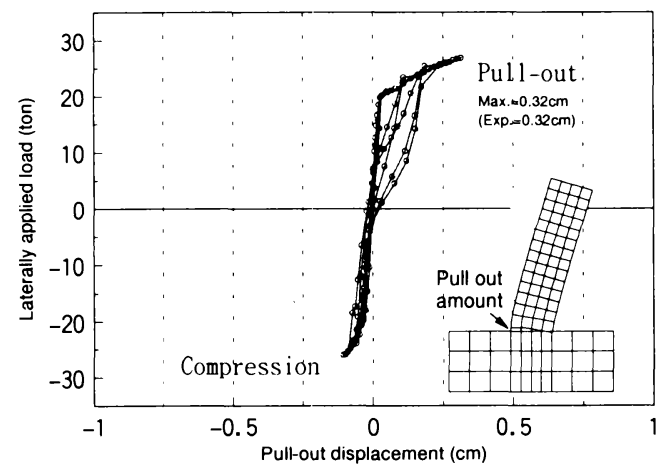

(a) Web reinforcement ratio $=0.04 \%$.

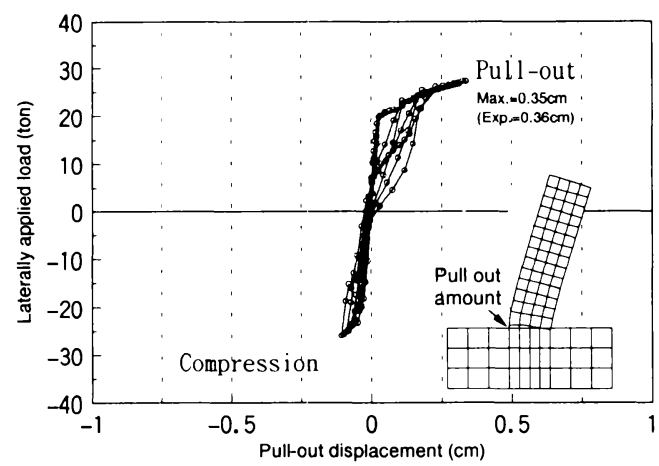

(b) Web reinforcement ratio $=0.16 \%$.

Fig. 15 Pull-out displacement from computation.

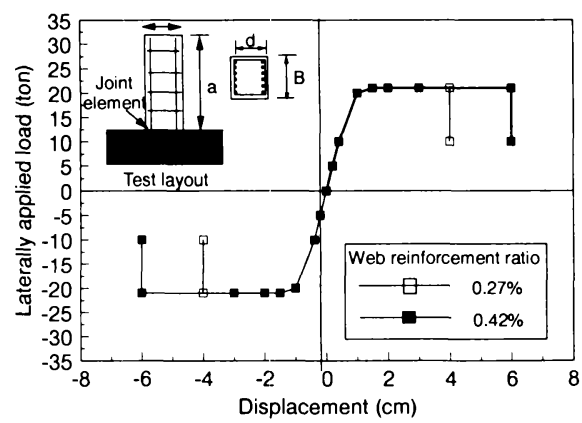

Fig. 16 Envelope of cyclic load-displacement relation of RC columns with different web reinforcement ratios ${ }^{12}$.

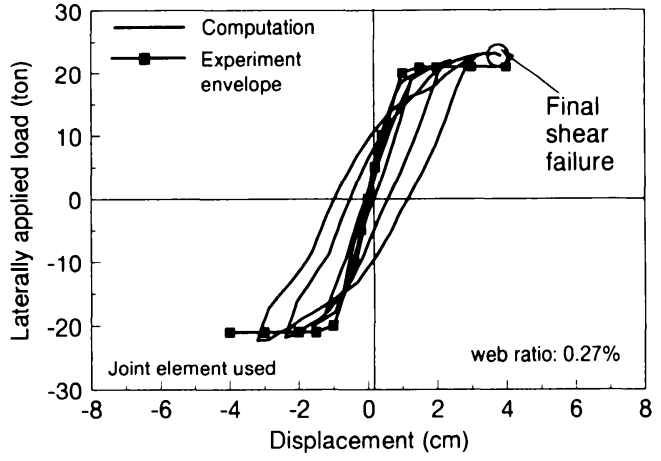

(a) Web reinforcement ratio $=0.27 \%$.

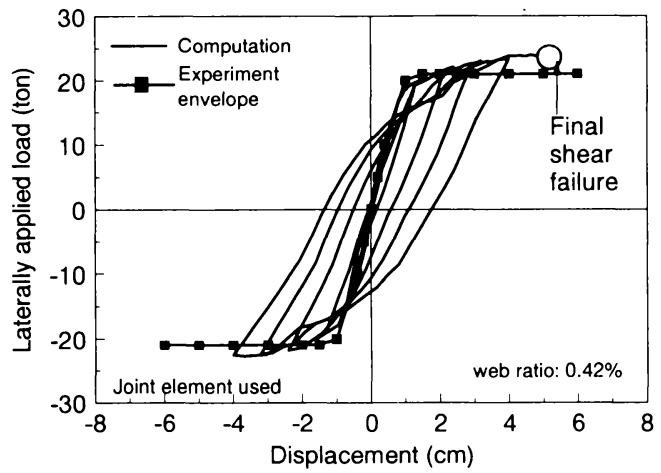

(b) Web reinforcement ratio $=0.42 \%$.

Fig. 17 FEM simulation concerning the effect of web ratio on ductility.

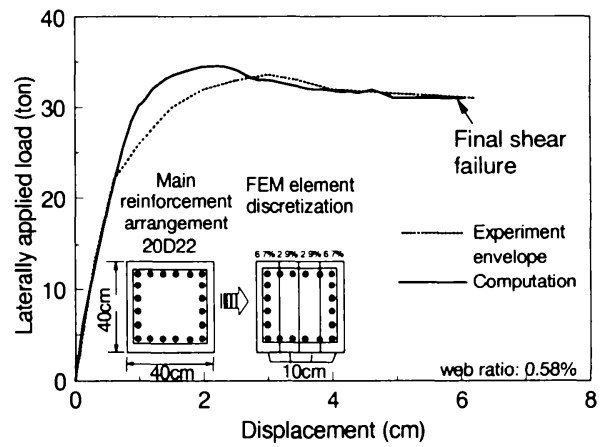

Fig. 18 FEM simulation for specimen with side reinforcement ${ }^{12)}$.

If the web reinforcement is increased up to $0.2 \%$ by volume, the shear capacity is increased but is still lower than two times of the shear force at yielding force. Then, this case still bring shear failure, but higher ductility ratio can be expected. When the web reinforcement is increased to $0.35 \%$, the shear capacity becomes higher than two times of the shear force at yielding point. In this case, brittle shear failure may be avoidable and the RC column may fail in flexure with high ductility.

All these cases are simulated in using nonlinear FEM as proposed in Chapter 2. The analytical 
Table 3 Failure mode prediction for large scale RC column.

\begin{tabular}{|c|c|c|c|c|}
\hline No. & 1 & 2 & 3 & 4 \\
\hline Width B (cm) & 200 & 200 & 200 & 200 \\
\hline Effective depth d $(\mathrm{cm})$ & 190 & 190 & 190 & 190 \\
\hline Shear span a/d & 2.0 & 2.0 & 2.0 & 2.0 \\
\hline $\begin{array}{c}\text { Main reinforcement } \\
\text { ratio }(\%)\end{array}$ & 0.4 & 0.4 & 0.4 & 0.4 \\
\hline $\begin{array}{c}\text { Web reinforcement } \\
\text { ratio }(\%)\end{array}$ & 0.05 & 0.15 & 0.20 & 0.35 \\
\hline $\mathrm{V}_{\mathrm{c}}\left(\mathrm{kgf} / \mathrm{cm}^{2}\right)$ & 3.9 & 3.9 & 3.9 & 3.9 \\
\hline $\mathrm{V}_{\mathrm{s}}\left(\mathrm{kgf} / \mathrm{cm}^{2}\right)$ & 1.5 & 4.5 & 6.0 & 10.5 \\
\hline $\mathrm{P}_{\mathrm{y}}\left(\mathrm{kgf} / \mathrm{cm}^{2}\right)$ & 7.0 & 7.0 & 7.0 & 7.0 \\
\hline$\left(\mathrm{V}_{\mathrm{c}}+\mathrm{V}_{\mathrm{s}}\right) / \mathrm{P}_{\mathrm{y}}$ & 0.8 & 1.2 & 1.4 & 2.1 \\
\hline$\mu(\mathrm{By} \mathrm{FEM})$ & $<1.0$ & 2.4 & 4.8 & 13.2 \\
\hline
\end{tabular}

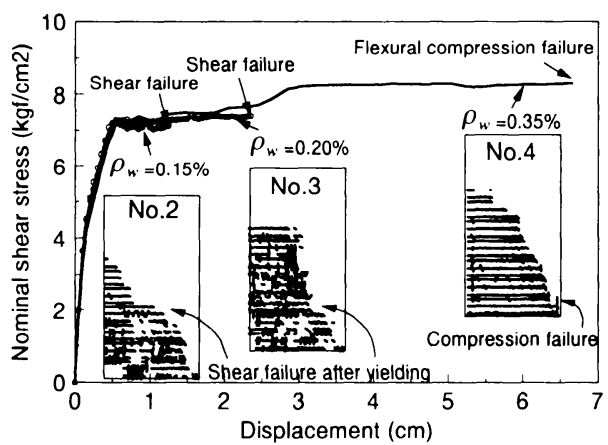

Fig. 19 Effect of web reinforcement ratio on ductility of large scale RC column in computation.

results under monotonic load are shown in Fig. 19. The failure mode is shown in the same figure with respect to crack patterns of the last computational step, that is the unstable failure point where progressive cracking is formed in iterative computation $^{2)}$. From the crack patterns, it can be seen that the RC column No.2 and No. 3 fail in shear mode after yield of main bars, but for No.4, the computation terminates in compression failure of concrete at extreme fiber close to the maximum moment section.

If the RC column is heavily reinforced by web steel and concrete is well confined by the web reinforcement, the compression failure of concrete is hardly brought about. Fig. 20a shows a RC beam having high web reinforcement ratio of $1 \%$. Here, the core concrete is fairly confined. The experimental result shows that only the cover concrete crushes, but the test can continue without further compression failure of core concrete (Fig. 20b).

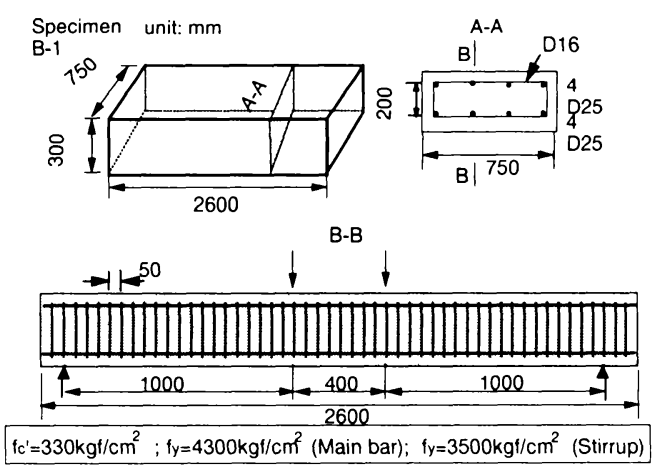

(a) Experimental layout of heavily placed web reinforcement $(1 \%)$.

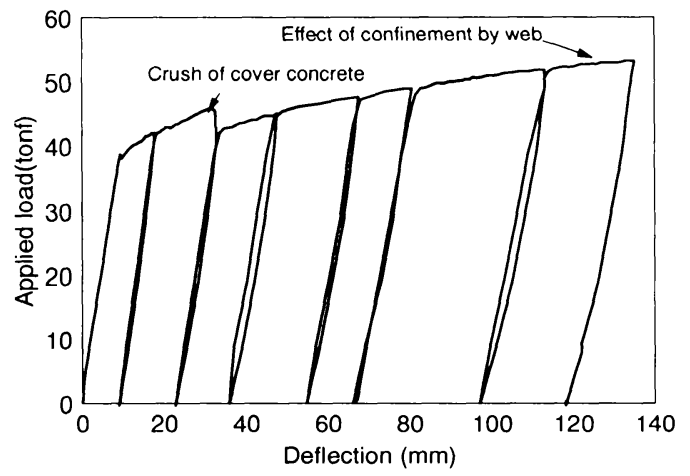

(b) High ductility level in the case of heavy confinement by large web reinforcement ratio $(1 \%)$.

Fig. 20 Experimental result of RC beam with high ductility level.

\section{PARAMETRIC STUDY ON DUCTILITY OF RC COLUMNS}

As stated in the previous section, FEM analytical method may be used for estimating ductility of RC columns with reasonable accuracy when failure mode is shear. Then, FEM analysis is applied for parametric study on factors that influence the deformability. In the computation, no repeating is carried out in each cyclic load step and in the constitutive model of RC, the spalling is not yet be included. The main factors on ductility have been empirically known, that is, main and web reinforcement ratios, axial force and shear span to depth $\mathrm{ratio}(\mathrm{a} / \mathrm{d})$ of the column. The sensitivity of these factors can be numerically examined, and some experimental results ${ }^{24)}$ will be employed for back check for versatility. The ranges of these parameters discussed are shown in Table 4. 
Table 4 The range of parameters that affect ductility.

\begin{tabular}{|c|c|c|}
\hline Parameter & FEM & Test [24] \\
\hline Main reinf. ratio (\%) & $0.9-2.1$ & $0.89--1.66$ \\
\hline Web reinf. ratio(\%) & $0.08--0.36$ & $0.08--0.23$ \\
\hline Axial comp. stress $\left(\mathrm{kgf} / \mathrm{cm}^{2}\right)$ & $0--20$ & $0-20$ \\
\hline $\mathrm{a} / \mathrm{d}$ & $3-6$ & $3-6$ \\
\hline
\end{tabular}

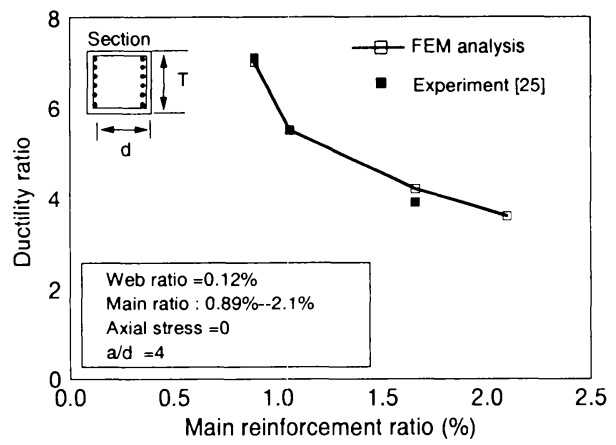

Fig. 21 Effect of main reinforcement ratio on ductility.

All the computations are carried out under monotonic load. Details of computational targets and the results are shown in Fig. 21 to Fig. 24. For computing ductility factor, the definition of yield displacement is rather different among technical reports and vague for sections with side reinforcement. Within the scope of this study, the authors intentionally select specimens without side reinforcement. In this case, definition of yield displacement when bars start to yield is quite explicit, because main reinforcement gets plastic at the same time under flexure. We can consistently adopt the experimentally reported ductility from different investigators. From these results, some tendencies are clearly identified again as follows.

- As the main reinforcement ratio increases, the ductility decreases.

- The increase in web reinforcement ratio elevates the ductility of RC columns.

- The ductility tends to decrease when higher axial compressive force is applied.

- As the shear span to depth $(\mathrm{a} / \mathrm{d})$ ratio increases, the ductility also increases.

Computed ductility ratios are summarized in Fig. 25, comparing with the experimental facts. It can be seen that the FEM simulation may give good prediction. The ductility associated with flexural action is out of discussion in this study, and further research on the buckling of bars and spalling of cover concrete will be needed.

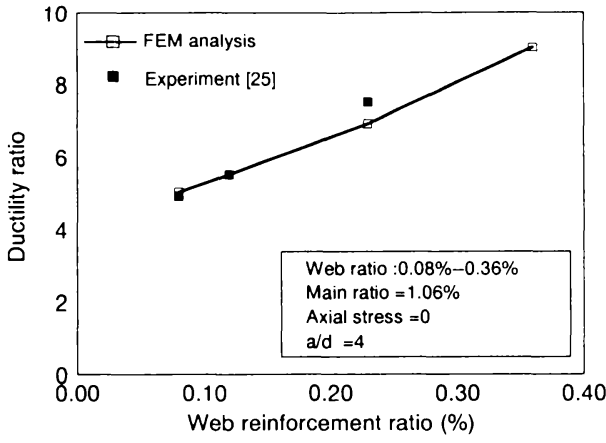

Fig. 22 Effect of web reinforcement ratio on ductility.

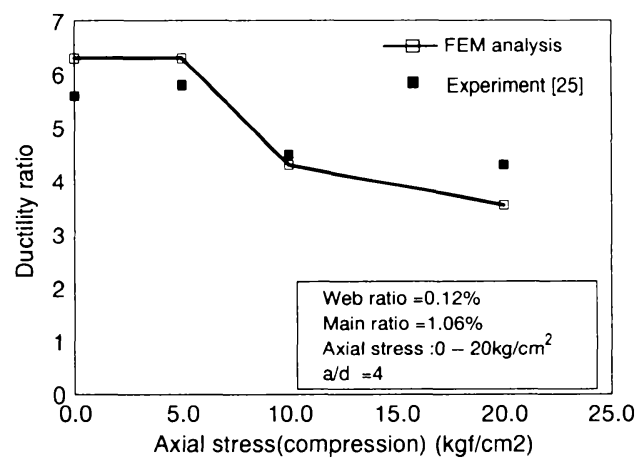

Fig. 23 Effect of axial stress on ductility.

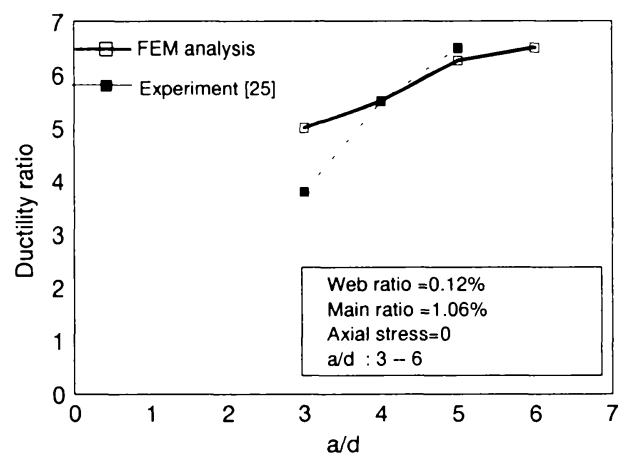

Fig. 24 Effect of a/d on ductility.

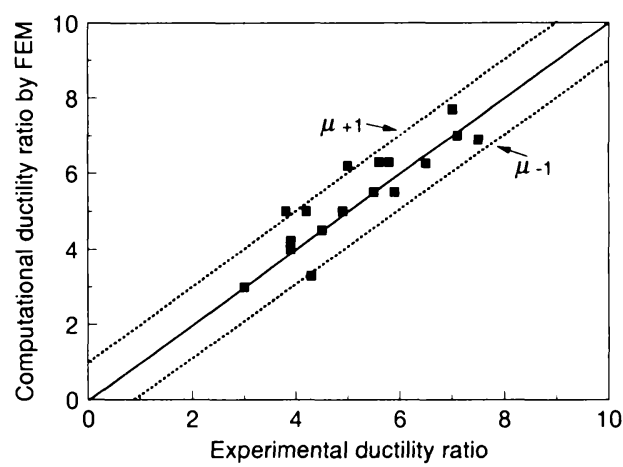

Fig. 25 Ductility ratio computed by FEM with the experimental results ${ }^{11), 12), 24)}$ 


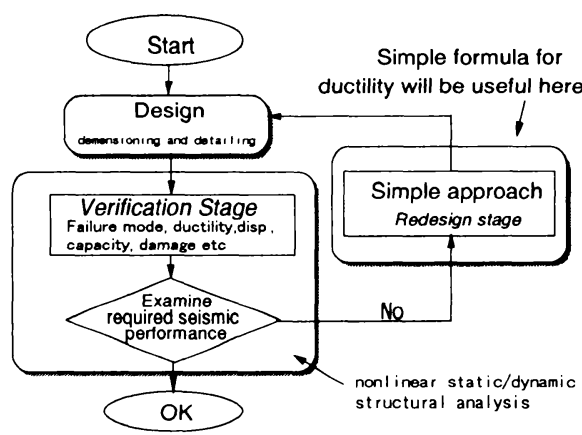

Fig. 26 Seismic resistant design and performance check system.

\section{SIMPLIFIED CHECK METHOD FOR FAILURE MODE}

\section{(1) General}

It was examined that nonlinear responses of RC lineal members can be traced up to unstable shear failure before and after yield of longitudinal reinforcement. Then, computed whole response under seismic actions can be a basis on which required seismic performances are examined. Fig. 26 shows a possible check-flowchart of seismic performance. In this scheme, nonlinear dynamic FEM analysis plays a substantial role of simulating nonlinear behavior on which required seismic performances are verified.

When an assumed structural dimensioning and detailing would not be accepted after checking the expected performances, some or all the designed articles on which decision was made at the design stage has to be changed (re-design stage in Fig. 26). At this stage, simple but reasonably accurate formula would be useful for practitioners who are requested to find out solutions which satisfy the performance requirements pass the examination.

In the re-design stage, prompt judgment on failure mode of RC members will be advisable. A proposal how to identify the inherent failure mode of members is shown in Fig. 27. If the shear capacity estimated is larger than the shear force when main reinforcement yields, the shear failure before yielding can be avoided. Many researches ${ }^{14), 15}$ ) show that shear failure occurs even after yield of steel occurs. It is now understood that the shear carrying capacity of concrete may decrease after plastic deformation of main reinforcement ${ }^{16), 17}$. Then, shear failure after yielding may occur if the decreased shear capacity gets smaller than the ultimate load corresponding to the ultimate strength of main reinforcement, as shown in Fig. 28. This kind of failure mode is also uninvited, since rather brittle failure with small displacement is accompanying.

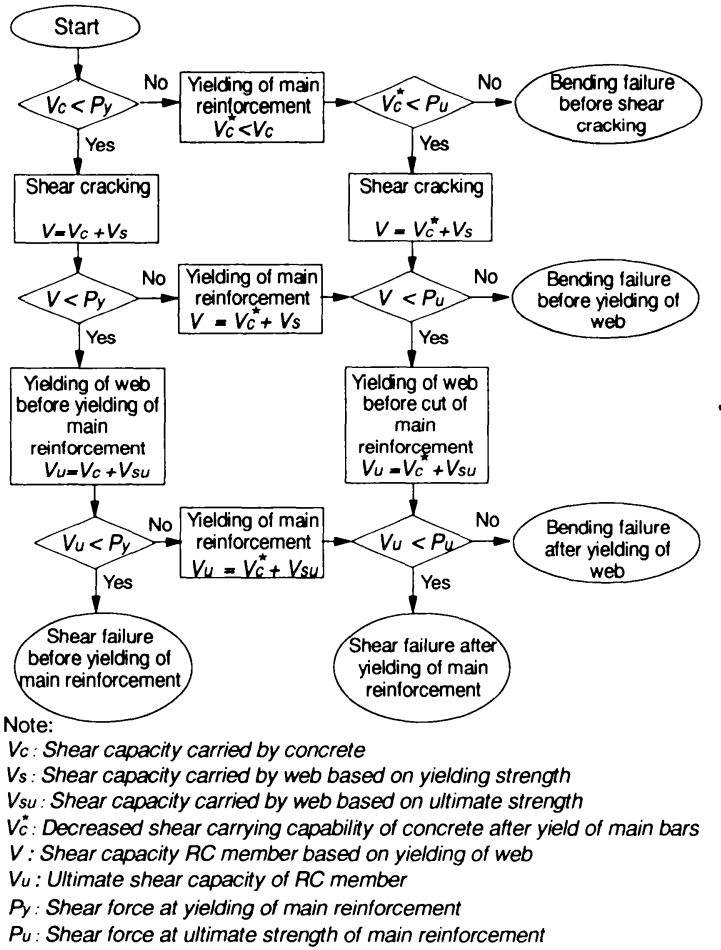

Fig. 27 Failure mode check-flowchart for RC column.
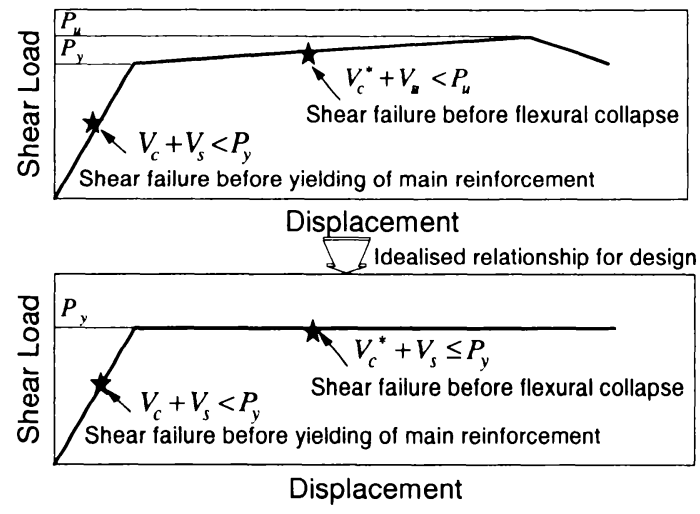

Fig. 28 Idealized shear load-displacement relationship of RC column.

In this section, a simple evaluation of shear capacity in post yield range is sought. In the last chapter, predicted ductility was found to be closer to the reality, and the influencing factors were clearly identified for sections without side reinforcement, within which the authors bound their discussions. In this discussion, analytically obtained sensitivity will be used for forming a degenerated simple formula of being re-design oriented in the scheme of seismic performance based design. 


\section{(2) Shear failure after yielding of main reinforcement}

The shear capacity when yield of web reinforcement occurs can be formulated as sum of the shear force carried by concrete and that carried by web reinforcement. Then, we have,

$$
\mathrm{V}=\mathrm{V}_{\mathrm{c}}+\mathrm{V}_{\mathrm{s}}
$$

where, $V:$ total shear capacity of a RC member (yield capacity of web reinforcement), $V_{c}$ : shear carrying capacity of concrete, $V_{s}$ : shear carrying capacity of web steel based on yield.

If the shear capacity is larger than the shear force when yield starts, shear failure before yielding can be avoided. Here, we have,

$$
\mathrm{V}>\mathrm{P}_{\mathrm{y}}
$$

where, $P_{y}$ : shear force that brings about yielding of longitudinal reinforcement.

As the shear force carried by concrete may decrease after plasticity of main reinforcement, the post-yield shear capacity can be formulated as,

$$
\mathrm{V}=\mathrm{V}_{\mathrm{c}}^{*}+\mathrm{V}_{\mathrm{s}}
$$

where, $V_{c}^{*}$ :decreased shear carrying capacity of concrete.

The reduction of shear capacity related to deformation and crack propagation is indirectly taken into account by using reinforcement ratio in the code equations when we discuss pre-yield shear failure of RC beams. Similarly, the shear carrying capacity of concrete decreases after yield of main reinforcement and the total shear potential also decreases. It may result in smaller capacity than the applied shear force, and finally cause the lower ductility. The decrease in shear carrying capacity of concrete is an important factor that affects the deformational behavior of RC column.

Reference [17] discusses the shear force carried by concrete and web steel. In several RC columns, the relation of total shear force and averaged stress in web steel was recorded and the shear force carried by web and concrete was investigated as shown in Fig. 29.

It can be seen in Fig. 29 that the shear stress in web increases as the shear force is getting larger. And the shear force carried by concrete is kept almost constant before yield of main reinforcement. But after the yielding of main reinforcement $(\mu=1, \mu$ is defined as ductility index), the shear becomes smaller and smaller as the shear stress in web continues to be elevated. This phenomenon can be explained such that the shear force carried by concrete will decrease after plasticity of main reinforcement. This decrease is also shown in Fig. 30.

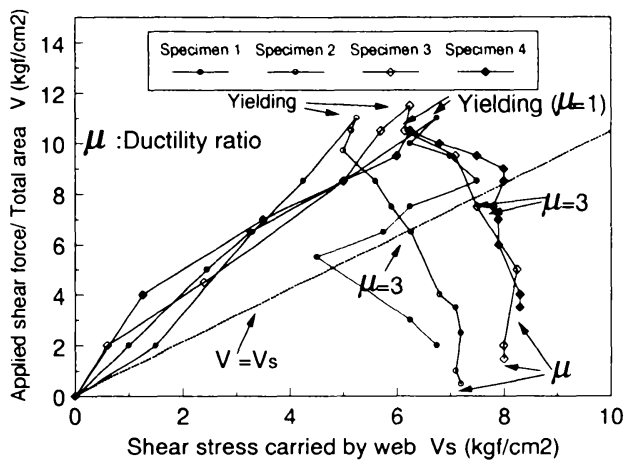

Fig. 29 Shear stress carried by web reinforcement from experiments $^{17}$.

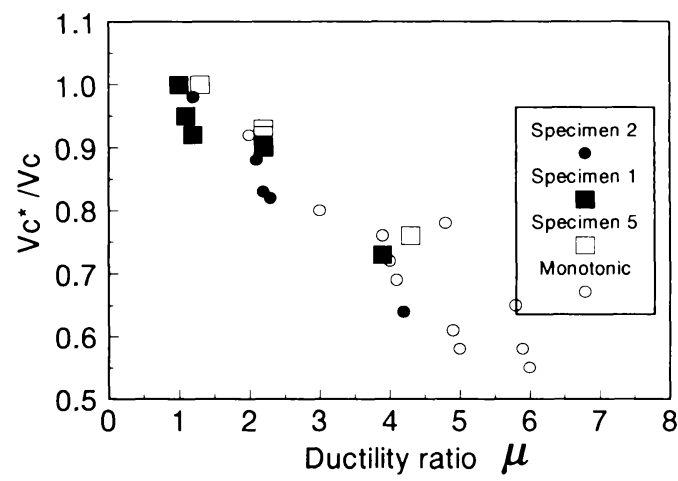

Fig. 30 Decrease in shear force carried by concrete after yielding of main reinforcement from experiments ${ }^{17)}$.

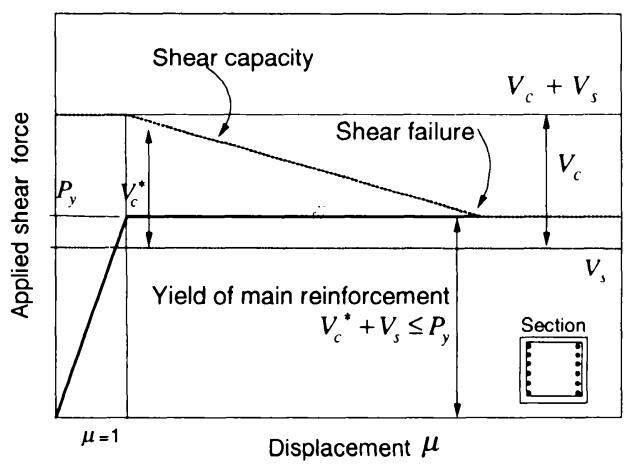

Fig. 31 Mechanism of shear failure after yielding of main reinforcement.

Based on the knowledge on the decaying shear capacity, post-yielding shear failure mechanism can be described as illustrated in Fig.31. As the shear carrying mechanism is not fully understood, the quantitative analytical approach is useful for describing the decrease in nominal shear force carried by concrete. 
In order to catch the decreasing shear capacity of concrete, about 200 experimental data of RC columns Ref. [15,18,19,20,21,22,23 and 24] were checked in this paper. There are 53 specimens that fail in post-yield shear failure mode. In these specimens, the main reinforcement ratio varies from $0.51 \%$ to $1.89 \%$, web reinforcement ratio from 0 to $0.23 \%$, axial compression stress from 0 to $30 \mathrm{kgf} / \mathrm{cm}^{2}$ and shear span to depth ratio ranges from 3 to 6 . Since all specimens have square sections without side reinforcement, the yield forces can be clearly calculated and easily detected in the experiments. Here, there exist two definitions on the ultimate deformation, one is to take the deformation corresponding to $80 \%$ of the maximum load after peak as the ultimate one, and another way is to indicate the deformation when the load decreases to the initial yield load after the peak. Reference [24] shows that these two kinds of definition lead to similar results when side reinforcement is not placed.

From Fig.31, it can be known that decreased shear capacity is close to the shear load of yielding point when shear failure takes place. So the decreased shear carrying capacity of concrete at shear failure can be inversely calculated by,

$$
\mathrm{V}_{\mathrm{c}}^{*}=\mathrm{P}_{\mathrm{y}}-\mathrm{V}_{\mathrm{s}}
$$

Reduction of shear capacity of concrete may be affected by several factors, such as reinforcement arrangement, shear span to depth ratio, axial force and concrete strength. All these factors also influence the ductility ratio of $\mathrm{RC}$ columns. The ductility ratio is generally defined as,

$$
\mu=\frac{\delta_{u}}{\delta_{y}}
$$

where, $\mu$ :ductility ratio, $\delta_{y}$ :displacement at yield point of main reinforcement, $\delta_{u}$ : ultimate displacement when unstable diagonal crack propoagation occures.

The JSCE code gives the formula for shear capacity carried by concrete as,

$$
V_{c}=0.9 \beta_{p}\left(\rho_{t}\right) \cdot \beta_{2}\left(f_{c}{ }^{\prime}\right) \cdot \beta_{d}(d)
$$

where, $\rho_{t}$ is the main reinforcement ratio. It can be assumed that the effect of larger deformation caused by plastic deformation of main reinforcement may be implicitly considered in shear capacity formula as,

$$
V_{c}^{*}=0.9 \beta_{p}\left(\rho_{e q}\right) \cdot \beta_{2}\left(f_{c}^{\prime}\right) \cdot \beta_{d}(d)
$$

where, $\rho_{e q}$ is the equivalent main reinforcement after yielding and $\rho_{e q}=\rho_{e q}(\mu)$.Then, we have,

$$
\frac{V_{c}^{*}}{V_{c}}=\varphi(\mu)
$$

Here, the decreased shear carrying capacity at failure point is described as a function of ductility ratio. From the experiment data, the relationship between decreased shear carrying capacity of concrete and ductility ratio (specimens with shear span to depth ratio being equal to 4) is shown in Fig. 32. From this figure, two main tendencies can be recognized. One is that the shear carrying capacity of concrete always decreases as the ductility ratio is larger. Another is that the relation of ductility ratio and shear carrying capacity of concrete at failure is close to a straight line as shown in Fig. 32.

The experimental results for different shear span to depth ratio are shown in Fig. 33. It can be found that for the specimen with larger shear span to depth ratio, the shear carrying capacity of concrete decreases more than those with smaller shear span to depth ratio.

Considering the experimental results shown in Fig. 32 and Fig. 33, one simple curve-fitting formula is empirically developed for describing the relationship between shear capacity and the ductility ratio as,

$$
\frac{V_{c}^{*}}{V_{c}}=(1-k(\mu-1))
$$

where, $V_{c}^{*}=V_{c}$ when $\mu<1 ; V_{c}^{*}=0$ when $\mu>1+1 / k$

$$
\mathrm{k}=\frac{1}{2(9-\mathrm{a} / \mathrm{d})}
$$

From Eq.17 and Eq.18, the ductility ratio of a designed column when shear failure occurs yields,

$$
\mu=1+\frac{1}{k}\left(1-\frac{\mathrm{P}_{\mathrm{y}}-\mathrm{V}_{\mathrm{s}}}{\mathrm{V}_{\mathrm{c}}}\right)
$$

where, $\mu<1$ when $V_{c}+V_{s}<P_{y} ; \mu>1+1 / k$ when $V_{s} \geq$ $P_{y}$. The ranges of application for this formula is shown in Fig.32 and Fig.33.

The predicted ductility ratios of $53 \mathrm{RC}$ columns are compared with the experimental results in Fig. 34. Even the results are a little scattered, the tendency still shows that the ductility ratio can be predicted roughly by this simplified method. The curve drawn here is just for RC columns without any side reinforcement. For versatile prediction, 3D effect of the presence of side reinforcement should be included in future. Then Eq.(19) will be compared with some existed formula for ductility prediction. 


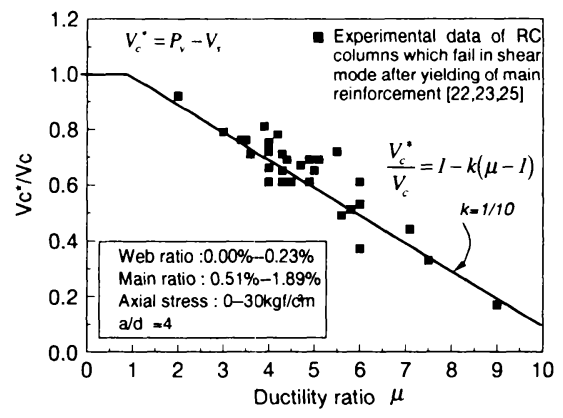

Fig. 32 Relationship between shear carrying capacity of concrete and ductility ratio $(\mathrm{a} / \mathrm{d}=4)$.

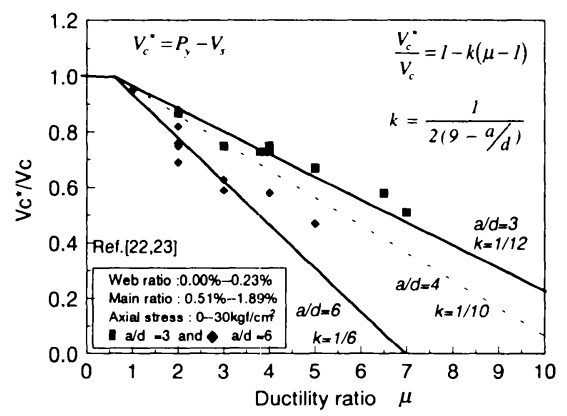

Fig. 33 Effect of $a / d$ on relation between shear carrying capacity of concrete and ductility ratio $(\mathrm{a} / \mathrm{d}=3--6)$.

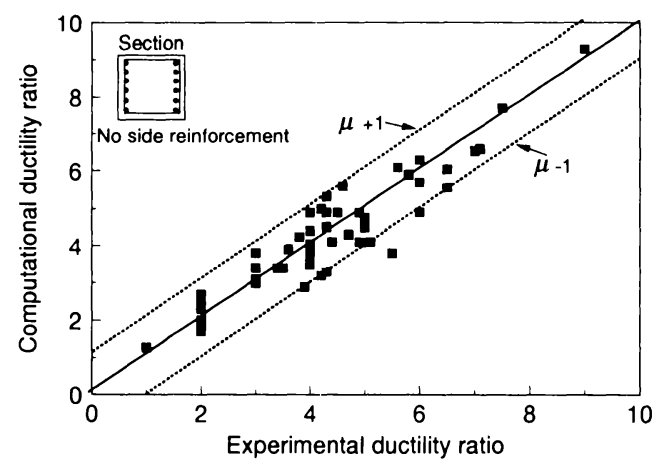

Fig. 34 Computational and computational ductility ratio.

\section{CONCLUSIONS}

From nonlinear failure analysis based on the spatial averaged constitutive laws for concrete and $\mathrm{RC}$, it was found that the large scale existing RC columns with few web reinforcement tend to fail in shear mode as the shear capacity is less than the shear load at yielding point of main reinforcement. For the seismic resistant design, it is needed to keep shear capacity and ductility enough to avoid sudden shear failure and to maintain the seismic energy absorption.

The shear failure occurs even after yield of main reinforcement as the shear carrying capacity by concrete may decrease according to the plastic deformation of reinforcement. FEM code proposed was used for simulating the shear failure and ductility of RC columns. It was verified that the FEM computation has fair agreement with experimental facts and can deal with large scale sections. As it was found in experiment that main reinforcement ,web reinforcement ratio, shear span to depth ratio and axial force may affect the ductility of RC columns, FEM was examined on how rationally the sensitivity of influencing factors would be predicted.

The FEM code can be used for examining the seismic resistant performance of structures that are designed beforehand. Aiming to develop a simple method to guide the re-design procedure, the relationship between reduced shear carrying capacity and ductility ratio at shear failure was built, and a simply formula was proposed to roughly estimate the ductility ratio of $\mathrm{RC}$ columns in the design loop.

The simple formula used for describing the decrease in shear carrying capacity of concrete is rather rough, and further research needs to be done for considering the effects such as the presence of side main reinforcement and axial force.

\section{REFERENCES}

1) Okamura, H., Maekawa, K., Ozawa, K. and Ohuchi, M.: Damage of concrete bridge piers, Journal of JSCE, Vol.80, No.4, pp.11-19,April, 1995.(in Japanese)

2) AN, X., Maekawa, K. and Okamura, H. : Numerical simulation of size effect in shear strength of RC beams, Journal of Materials, Concrete Structures and Pavements, No.564/V-35, pp297-316, 1997.

3) Okamura, H. and Maekawa, K. : Nonlinear Analysis and Constitutive Models of Reinforced Concrete, GihodoShuppan, Tokyo, Japan, 1991.

4) Okamura, H. and Maekawa, K. : Reinforced concrete design and size effect in structural nonlinearity, invited paper, Proceeding of JCI International Workshop on Size Effect, Sendai, Japan, pp.1-20,1993.

5) Maekawa,K. and Hasegawa, T. : The state-of-the-art on constitutive laws of concrete, Concrete Journal, Vol.32, No.5, pp.13-22, 1994.

6) Li, B., Maekawa, K. and Okamura, H. : Contact density model for stress tranfer across cracks in concrete, Journal of the Faculty of Engineering, University of Tokyo (B), Vol.40, No.1, pp.9-52, 1989.

7) Tepfers,R. : A theory of bond applied to overlapped tensile reinforcement splices for deformed bars, Publication 73:2, Division of Concrete Structures, Chalmers University of Technology, Goteborg, Sweden, 1973.

8) Jinno, Y. Fujii, S., et al. : Bar size effect on bond characteristics with splitting of surrounding concrete, Summaries of technical papers of annual meeting, AIJ, pp747-748, 1986.

9) Bazant, Z.P. and Oh, B.H. : Crack band theory for fracture of concrete, Material and Structures, (RILEM, Prais), Vol.16, pp155-157, 1983. 
10) JSCE, Standard specification for design and construction of concrete structure, pert I (Design), Ist ed, Tokyo, 1986.

11) Ohta, M. : A study on earthquake resistant design for reinforced concrete bridge piers of single-column type, Report of civil research institute, No.153, March 1980. (in Japanese)

12 Ishibashi, T. and Yoshino, S. : Study on deformation capacity of reinforced concrete bridge piers under earthquake, Journal of JSCE, No.390/V-8, 1988. (in Japanese)

13) JSCE, Standard specification for seismic resistant design of concrete structure, 1st ed, Tokyo, 1996

14) Kobayashi, N. , Kashiwazaki, T. and Noguchi, H. : A study on shear deterioration after flexural yielding of reinforcement concrete beams, Proc. of JCI, Vol.17, No.2, pp.571576,1995. (in Japanese)

15) Higai, T. , Niwa, J. and Okamura, Y. : Considerations on the post-yield shear failure mechanism of RC members, Proc. of $J C I$, Vol.8, No.2, pp.329-334, 1987. (in Japanese)

16) Muguruma, H. and Watanabe, F. : Effect of yielding in web reinforcement upon the shear deformation capacity of reinforced concrete column, Proc. of JCI, Vol.1, pp.333336,1979 . (in Japanese)

17) Muguruma, $H$. and Watanabe, F. : Strength evaluation of $R / C$ column failing in shear, Proc. of JCI, Vol.7, No.2, pp.541544, 1985. (in Japanese)

18) Higai, T. , Rizkalla, S. Ben-omran, H. and Saadat, F.: Shear failure of reinforcement members subjected to large deflection reversals, Proc. of JCI, Vol.6, pp.505-508, 1984. (in Japanese)
19) Higai, T.: Ductility of reinforced concrete members failing in shear due to large deflection reversals, Proc. of JCl, Vol.8, pp.769-772, 1986. (in Japanese)

20) Arakawa, T. and Fujita, Y. : Effectiveness of shear reinforcement on deformation behavior of reinforced concrete columns subjected to cyclic loading, Proc. of $\mathrm{JCI}$, Vol.2, pp.457-460, 1980. (in Japanese)

21) Arakawa, T., Arai, Y., Fujita, Y. and Mizoguchi, M. Evaluation for deformation behavior of reinforced concrete columns under cyclic loading, Proc. of JCI, Vol.2, pp.449452, 1981. (in Japanese)

22) Arakawa, T., Arai, Y., Fujita, Y. and Egashira, K. : Effects of cyclic loading rate on the load-carrying capacity and inelastic behavior of reinforced concrete columns, Proc. of JCI, Vol.4, pp.325-328, 1982. (in Japanese)

23) Arakawa, T., Arai, Y., Egashira, K. and Ohkubo, S.: Cyclic behavior and evaluation of inelastic capacity of reinforced concrete columns, Proc. of JCI, Vol.5, pp.305-308, 1983. (in Japanese)

24) Machida, A., Mutsuyoshi, H. and Toyoda, K. : Evaluation of the ductility of reinforced concrete members, Journal of JSCE, No.378/V-6, pp.203-212, 1987.(in Japanese)

26) Bujadham, B. and Maekawa, K. : The universal model for stress transter across cracks in concrete, Proc.of JSCE, No.451/V-17, pp277-287, 1992.

(Received March 18,1997)

\section{鉄筋降伏以後の R C 柱のせん断抵抗とじん性}

\section{安雪暉・前川宏一}

本研究は, 耐震性能評価設計を念頭に置き, 鉄筋コンクリート柱の主鉄筋降伏以後のせん断酎力と変形 性能に関する数値解析法を提示するものである. 大型構造物を対象範囲に包含するものとし, 降伏以後の せん断举動に関して, 有限要素解析結果と実験結果の比較を行い, 適用性を評価した。また, 側方鉄筋の無 い梁について影暜因子の感度解析を行い, その結果を概括する目的で簡単な評価式を提示した. 